\title{
INFLUENCE OF CUTTING FLUID FLOW RATE AND CUTTING PARAMETERS ON THE SURFACE ROUGHNESS AND FLANK WEAR OF TIAIN COATED TOOL IN TURNING AISI 1015 STEEL USING TAGUCHI METHOD
}

\begin{abstract}
This paper presents the influence of cutting parameters (Depth of cut, feed rate, spindle speed and cutting fluid flow rate) on the surface roughness and flank wear of physical vapor deposition (PVD) Cathodic arc evaporation coated TiAlN tungsten carbide cutting tool insert during CNC turning of AISI 1015 mild steel. Analysis of Variance has been applied to determine the critical influence of cutting parameters. Taguchi orthogonal test design has been employed to optimize the process parameters affecting surface roughness and tool wear. Depth of cut was found to be the most dominant factor contributing to high surface roughness $(67.5 \%)$ of the inserts. However, cutting speed, feed rate and flow rate of cutting fluid showed minimal contribution to surface roughness. On the other hand, cutting speed (45.6\%) and flow rate of cutting fluid (23\%) were the dominant factors influencing tool wear. The optimum cutting conditions for desired surface roughness constitutes the following parameters such as medium cutting speed, low feed rate, low depth of cut and high cutting fluid flow rate. Minimal tool wear was achieved for the following process parameters such as low cutting speed, low feed rate, medium depth of cut and high cutting fluid flow rate.

Keywords: TiAlN coated inserts, Surface roughness, Flank wear, Taguchi method, ANOVA
\end{abstract}

\section{Introduction}

The latest developments in science and technology had put tremendous pressure on manufacturing and machining engineering. Various process parameters have been involved in machining and finding out the optimal parameters for best quality is a major challenge in increasing the performance of manufacturing using available resources. The need for improving productivity and boosting their quality by the manufacturing segment has been the driving force after the development of cutting tool materials [1].

Turning is one of the underlying machining processes, mainly for the finishing of machined parts. The developing technology of Hard turning that offers many potential advantageous compared to grinding, which remains the standard complete process for critical hardened steel surfaces [2,3]. The life of cutting tools plays a key role in increasing productivity and accordingly is an important economic factor. Major improvement in cutting tool technology is the introduction of thin hard film surface coatings on cutting tool that protects the tool from oxidation and abrasion and thereby increases the life of cutting tools [4]. Coating has been also used for improving lubrication at the tool-chip and tool-work piece interfaces and to decrease friction, and temperature at the cutting edge while machining [5]. For turning process, the cutting conditions such as Speed,
Feed and Depth of cut plays a major role in the efficient use of a machine tool [6].

Taguchi method provides, a powerful and systematic path to optimized designs like performance, quality, and cost. This method has been successfully implemented in a designing reliable and higher quality products at lowest cost in manufacturing areas $[7,8]$. An orthogonal array, Analysis of Variance (ANOVA) and signal to noise $(\mathrm{S} / \mathrm{N})$ ratio has been employed to carry out the cutting characteristics of AISI 304 austenitic stainless steel work piece using $\mathrm{TiC}$ and $\mathrm{TiCN}$ coated tungsten carbide cutting tools [9]. From many literatures, Cutting speed is observed to be the most significant parameter that affects the flank wear and Feed rate affects dominantly the surface roughness [10]. The various cutting fluid flow conditions and cutting parameters on surface roughness and tool flank wear indicates the application of cutting fluid (13.7\%) shows the substantial contribution, while the feed rate provides the minimum contribution to tool wear $[9,11]$.

The purpose of this work is to prove an application of Taguchi parameter design in order to predict the optimum surface roughness and Flank wear among a particular combination of input turning parameters (Speed, Feed rate, depth of cut and cutting fluid flow rate) in turning mild steel work piece. After turning, confirmation test is done to validate surface roughness and flank wear with experimental values. The basic turning operation of work piece was shown in Fig. 1. 


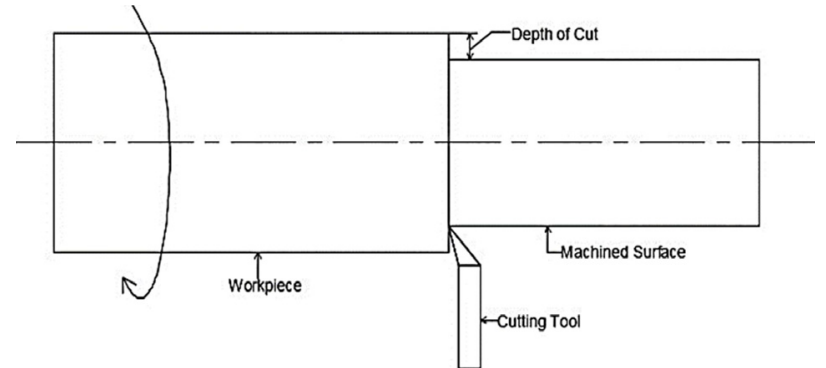

Fig. 1. Basic Turning Operation

\section{Experimental procedure}

\subsection{Selection of cutting tool and work material}

In this experimental study, commercially available Tungsten carbide CNC inserts manufactured by Sandvik were used and its chemical composition is listed in Table 1. The CNC insert tip is in the form of diamond bar of diameter $40 \mathrm{~mm}$ and $1.2 \mathrm{~cm}$ length of cutting edge. The hardness of Tungsten carbide $\mathrm{CNC}$ insert was found to be $14.47 \mathrm{GPa}$. The inserts have the geometry of ISO designation CNMG 120408 (80 ${ }^{\circ}$ diamond shaped insert) with negative rake angle and nose radius of $0.8 \mathrm{~mm}$. The inserts were tightly mounted on a tool holder designated by ISO as PCLNR 2525 M12. TiAlN coating was deposited on nine Tungsten carbide inserts by cathodic arc evaporation method from commercially available industrial Blazers (Orelikon blazers).

TABLE 1

Chemical Composition of Tungsten Carbide Insert

\begin{tabular}{|c|c|c|c|c|c|}
\hline \hline Element & $\begin{array}{c}\text { Tungsten } \\
\text { carbide }\end{array}$ & $\begin{array}{c}\text { Titanium } \\
\text { carbide }\end{array}$ & $\begin{array}{c}\text { Tantalum } \\
\text { carbide }\end{array}$ & Cobalt & $\begin{array}{c}\text { Molybdenum } \\
\text { Carbide }\end{array}$ \\
\hline Weight (\%) & $91-93.2$ & 0.32 & $0.89-1.02$ & $5.3-6.1$ & Traces \\
\hline
\end{tabular}

Mild steel was used as work material and it includes C, $\mathrm{Mn}, \mathrm{Si}, \mathrm{S}$ and P [12]. A $3 \mathrm{~m}$ long SAE-AISI 1015 grade mild steel rod was cut into smaller specimens of $110 \mathrm{~mm}$ length and $50 \mathrm{~mm}$ diameter. The chemical composition of AISI 1015 mild steel is listed in Table 2.

TABLE 2

Chemical Composition of AISI 1015

\begin{tabular}{|c|c|c|c|c|c|}
\hline \hline Element & Carbon & Silicon & Manganese & Sulphur & Phosphorus \\
\hline $\begin{array}{c}\text { Weight } \\
(\%)\end{array}$ & $0.16-0.15$ & $\begin{array}{c}0.40 \\
\max \end{array}$ & $0.70-0.90$ & $\begin{array}{c}0.040 \\
\max \end{array}$ & $0.040 \max$ \\
\hline
\end{tabular}

\subsection{Machining process}

Turning experiments were performed in wet conditions (Low, Medium \& High flow rates of cutting fluid) using JOBBER XL CNC turning center with $7.5 \mathrm{~kW}$ spindle power. The surface roughness $\left(R_{a}\right)$ and flank wear $(\mathrm{Vb})$ were measured to inspect the effect of various cutting parameters. The range of cutting parameters were selected based on machining data handbook as listed in Table 3. A Mitutoyo SJ-410 surface roughness equipment was used to measure the roughness of surface at various positions of the specimen with a tracing speed of stylus is $0.3 \mathrm{mms}^{-1}$. A Scientico tool maker's microscope was used to measure Flank wear.

TABLE 3

Selection of cutting parameters

\begin{tabular}{|c|c|c|c|}
\hline \hline \multirow{2}{*}{ Parameters } & \multicolumn{3}{|c|}{ Level for each Parameters } \\
\cline { 2 - 4 } & Level 1 & Level 2 & Level 3 \\
\hline Cutting Speed, $V c(\mathrm{~m} / \mathrm{min})$ & 500 & 550 & 600 \\
\hline Feed Rate, $F(\mathrm{~mm} / \mathrm{rev})$ & 0.05 & 0.1 & 0.15 \\
\hline Depth of Cut, DOC $(\mathrm{mm})$ & 1 & 1.5 & 2 \\
\hline Cutting Fluid Flow Rate, $Q\left(\mathrm{~m}^{3} / \mathrm{s}\right)$ & Low & Medium & High \\
\hline
\end{tabular}

\subsection{Taguchi method and design of experiments}

In this work, Taguchi's parameter design approach is used to investigate the effect of process parameters cutting speed, feed rate, depth of cut and cutting flow rates on surface roughness, flank wear while turning mild steel by TiAlN coated tool. If a full factorial design is applied, 81 experiments study must be conducted. However, the experimental study is expensive and time-consuming. So Taguchi orthogonal array was carried out to minimize the number of experiments [9]. Correspondingly, nine experiments are sufficient for three parameters based on Taguchi orthogonal array design.

[Degree of freedom $=$ Number of level -1$]$

Here, there are eight degrees of freedom owing to 3 machining input parameters. So Taguchi L9 orthogonal array was selected for further study.

\subsection{Signal to noise $S / N$ ratio}

It is a measure used in science and engineering that compares the level of a required signal to the level of background noise. It is also well-defined as the ratio of signal power to noise power, often expressed in decibels $(\mathrm{dB})$. The Cutting parameters that influence the output can be classified into two classes, namely controllable (signal) and uncontrollable (noise) factors. The $S / N$ ratio is used to measure the quality characteristic devious from the desired value [13]. The $S / N$ ratio for surface roughness and flank wear was calculated based on smaller the better condition as described in below equation.

$$
S N_{S}=-10 \log \left(S y^{2} / n\right)
$$

where, $n$ is the number of experiments, and $y$ is the measured value. Based on the experiment $S / N$ ratios were obtained for surface roughness and flank wear. The value of $S / N$ ratios are listed in Table 4. The optimum level of cutting parameters can be found by considering the highest value of $S / N$ ratio [14]. 
Surface roughness and Flank wear obtained from experiments

\begin{tabular}{|c|c|c|c|c|c|c|c|c|}
\hline \multirow[b]{2}{*}{$\begin{array}{l}\text { Trail } \\
\text { No }\end{array}$} & \multicolumn{4}{|c|}{ Cutting Parameter Level } & \multicolumn{2}{|c|}{ Performances } & \multicolumn{2}{|c|}{$S / N$ ratio $(\mathrm{dB})$} \\
\hline & $\begin{array}{c}\text { Cutting speed, } \\
\text { Vc }\end{array}$ & Feed rate, $F$ & $\begin{array}{c}\text { Depth of cut, } \\
\text { DOC }\end{array}$ & $\begin{array}{l}\text { Cutting Fluid } \\
\text { Flow rate, } Q\end{array}$ & $\begin{array}{c}\text { Surface } \\
\text { Roughness, } R a \\
(\mu \mathrm{m})\end{array}$ & $\begin{array}{c}\text { Flank wear, } \\
\text { Vb } \\
(\mathrm{mm})\end{array}$ & $\begin{array}{c}\text { Surface } \\
\text { Roughness }\end{array}$ & Flank wear \\
\hline 7 & 500 & 0.05 & 1.0 & Low & 0.220 & 0.455 & 13.15 & 6.84 \\
\hline 5 & 500 & 0.10 & 1.5 & Medium & 0.315 & 0.325 & 10.03 & 9.76 \\
\hline 3 & 500 & 0.15 & 2.0 & High & 0.223 & 0.410 & 13.03 & 7.74 \\
\hline 1 & 550 & 0.05 & 1.5 & High & 0.234 & 0.315 & 12.62 & 10.03 \\
\hline 8 & 550 & 0.10 & 2.0 & Low & 0.233 & 0.665 & 12.65 & 3.54 \\
\hline 6 & 550 & 0.15 & 1.0 & Medium & 0.209 & 0.550 & 13.60 & 5.19 \\
\hline 4 & 600 & 0.05 & 2.0 & Medium & 0.229 & 0.522 & 12.80 & 5.65 \\
\hline 2 & 600 & 0.10 & 1.0 & High & 0.207 & 0.680 & 13.68 & 3.35 \\
\hline 9 & 600 & 0.15 & 1.5 & Low & 0.273 & 0.735 & 11.28 & 2.67 \\
\hline \multicolumn{5}{|c|}{ Total } & 2.143 & 4.657 & 112.84 & 54.77 \\
\hline \multicolumn{5}{|c|}{ Mean } & 0.238 & 0.517 & 12.54 & 6.09 \\
\hline
\end{tabular}

\section{Results and discussion}

\subsection{Analysis of variance}

Analysis of variance (ANOVA) is used to inquire which design parameter affects the quality characteristics significantly. This is achieved by separating the total variability of the $S / N$ ratio, which is measured by the sum of the squared deviations from the total mean of $S / N$ ratio, and contributions by individual design parameters. The total sum of squared deviations $S S_{T}$ from the total mean $S / N$ ratio $\eta m$ can be calculated as,

$$
S S_{T}=\sum_{i=1}^{n}(\eta i-\eta m)^{2}
$$

Where, $n$ is the number of experiments and $\eta i$ is the mean of $\mathrm{S} / \mathrm{N}$ ratio for the $i^{\text {th }}$ experiment.

ANOVA results for surface roughness and flank wear which is used to find out the percentage contribution of each and every parameter on surface roughness and flank wear was listed in Table 5. From the results, it was viewed that depth of cut and cutting fluid flow rates were the most significant cutting parameters that affects surface roughness. The percentage contribution of cutting parameters for surface roughness such as depth of cut, cutting fluid flow rate, cutting speed, and feed rate were calculated from ANOVA as $67.55 \%, 14 \%, 10.71 \%$ and $7.74 \%$ respectively. Further it was observed that cutting speed is the most significant cutting parameters that affects the flank wear. Similarly the percentage contribution of cutting speed, cutting fluid flow rate, depth of cut, and feed rates for flank wear were calculated as $45.61 \%, 23.04 \%, 15.68 \%$ and $15.67 \%$ respectively.

\subsection{Comparison of predicted and experimental results at the optimal cutting conditions}

The optimum cutting conditions were predicted by using the estimated signal to noise ratio [14]. From Fig. 2 the optimum cutting parameters were identified as A2B1C1D3 where A is cutting speed, B is feed rate, $C$ is the depth of cut and D is cutting fluid flow rate. The estimated $S / N$ ratio using the design parameters for optimum level was calculated as,

$$
\hat{\eta}=\eta m+\sum_{i=1}^{o}(\eta i m-\eta m)
$$

where, $\eta m$ is the total mean $S / N$ ratio, $\eta i m$ is the mean of $S / N$ ratio at the optimum level, and $o$ is the number of the main design parameters which affect the quality.

Consequently, the prediction of $S / N$ ratio was computed as 13.98, enumerated in Table 6. After the confirmation test, level A2B1C1D3 sights the value of $S / N$ ratio as 15.53 which is nearer to predicted value.

TABLE 5

ANOVA for Surface Roughness and Flank Wear

\begin{tabular}{|c|c|c|c|c|c|c|c|c|}
\hline \hline \multicolumn{4}{|c|}{ Analysis of Variance (ANOVA) for Surface Roughness } & \multicolumn{3}{c|}{ Analysis of Variance (ANOVA) for Flank wear } \\
\hline Parameter & $\begin{array}{c}\text { Degree of } \\
\text { freedom }\end{array}$ & $\begin{array}{c}\text { Sum of } \\
\text { squares }\end{array}$ & Mean square & $\begin{array}{c}\text { Contribution } \\
\mathbf{( \% )}\end{array}$ & $\begin{array}{c}\text { Degree of } \\
\text { freedom }\end{array}$ & $\begin{array}{c}\text { Sum of } \\
\text { squares }\end{array}$ & $\begin{array}{c}\text { Mean square } \\
\text { Contribution } \\
\mathbf{( \% )}\end{array}$ \\
\hline Vc & 2 & 1.18 & 0.59 & 10.71 & 2 & 26.91 & 13.46 & 45.61 \\
\hline F & 2 & 0.85 & 0.43 & 7.74 & 2 & 9.25 & 4.62 & 15.67 \\
\hline DOC & 2 & 7.43 & 3.71 & 67.55 & 2 & 9.26 & 4.63 & 15.68 \\
\hline Q & 2 & 1.54 & 0.77 & 14.00 & 2 & 13.59 & 6.80 & 23.04 \\
\hline Total & 8 & 11.00 & 5.50 & 100 & 8 & 59.01 & 29.51 & 100 \\
\hline
\end{tabular}


TABLE 6

Confirmation test for Surface Roughness

\begin{tabular}{|c|c|c|c|}
\hline \multicolumn{4}{|c|}{ Confirmation test for Surface Roughness } \\
\hline & Initial & Prediction & Experiment \\
\hline Parameter Level & A3B3C3D1 & A2B1C1D3 & A2B1C1D3 \\
\hline Surface Roughness $(\mu \mathrm{m})$ & - & - & 0.19 \\
\hline$S / N$ ratio $(\mathrm{dB})$ & 12.46 & 13.98 & 15.53 \\
\hline Improvement & & 3.07 & \\
\hline
\end{tabular}

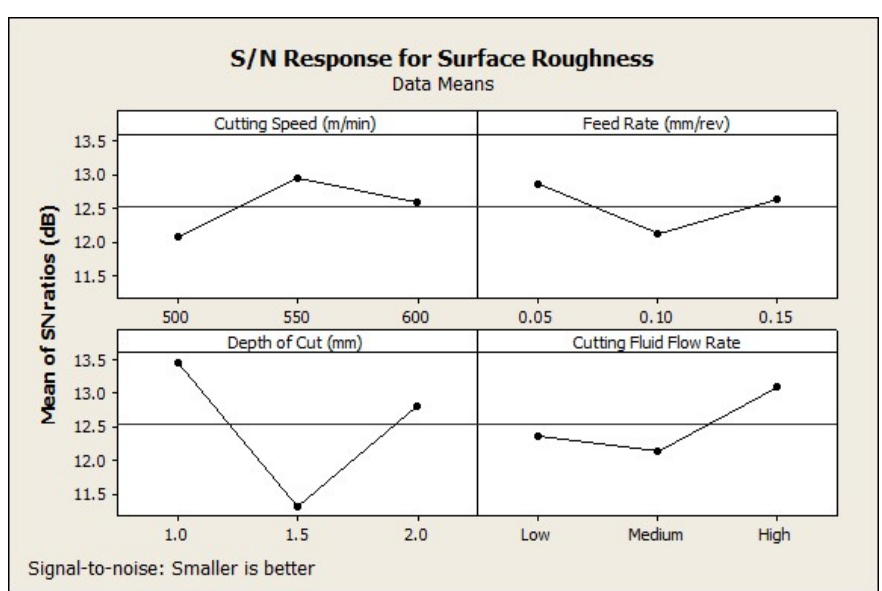

Fig. 2. $S / N$ Response for Surface Roughness

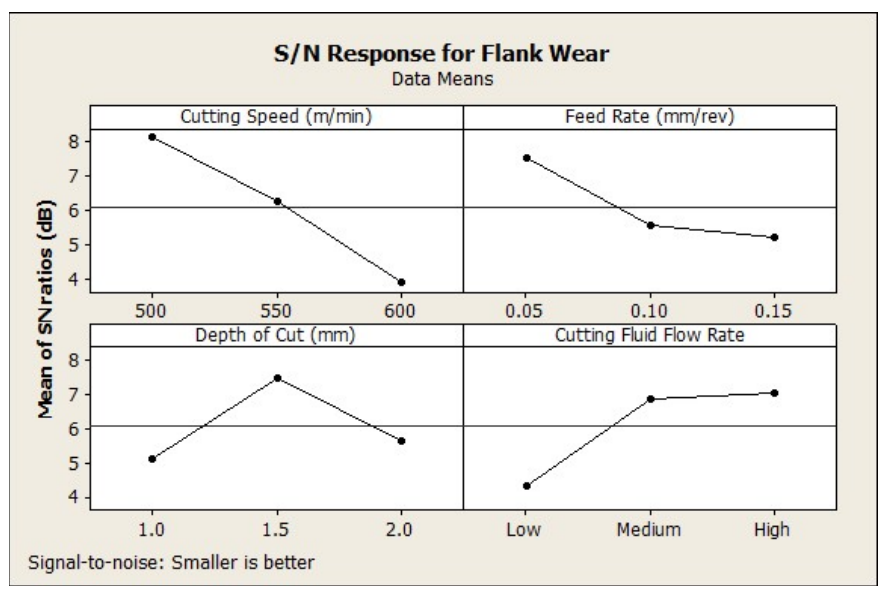

Fig. 3. $S / N$ Response for Flank Wear

From Fig. 3 the optimum cutting parameters were identified as A1B1C2D3. Thus, the prediction of $S / N$ ratio was computed as 10.80 , listed in Table 7. After confirmation test, resultant level A1B1C2D3 sights the value of $S / N$ ratio as 11.95 which is nearer to the predicted value.

TABLE 7

Confirmation test for Tool Wear

\begin{tabular}{|c|c|c|c|}
\hline \hline \multicolumn{4}{|c|}{ Confirmation test for Tool Wear } \\
\hline & Initial & Prediction & Experiment \\
\hline Parameter Level & A2B2C3D2 & A1B1C2D3 & A1B1C2D3 \\
\hline Flank Wear (mm) & & & 0.29 \\
\hline S/N ratio (dB) & 5.72 & 10.80 & 11.95 \\
\hline Improvement & & 6.23 & \\
\hline
\end{tabular}

\subsection{Effect of Individual Parameters on Responses}

\subsubsection{Response for Surface Roughness}

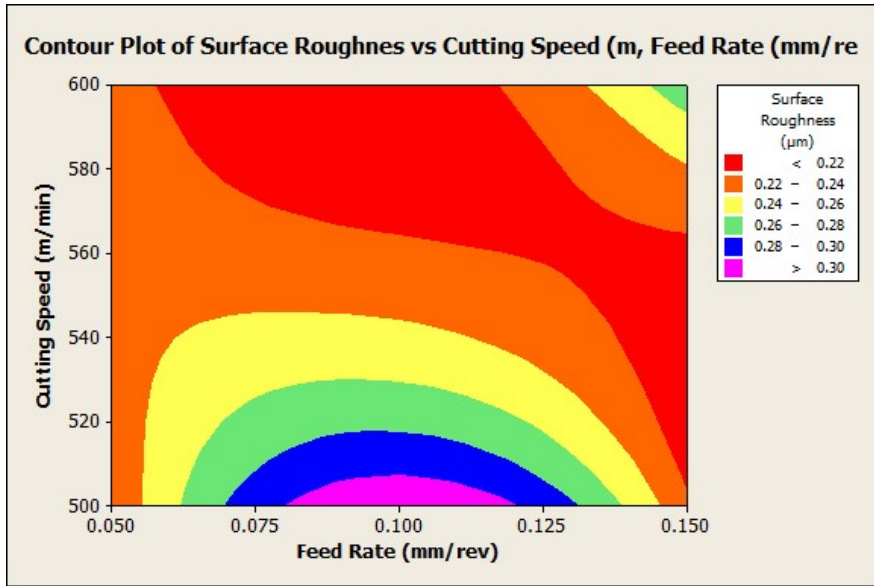

Fig. 4. (a) Response for Surface roughness - Cutting speed vs. Feed rate

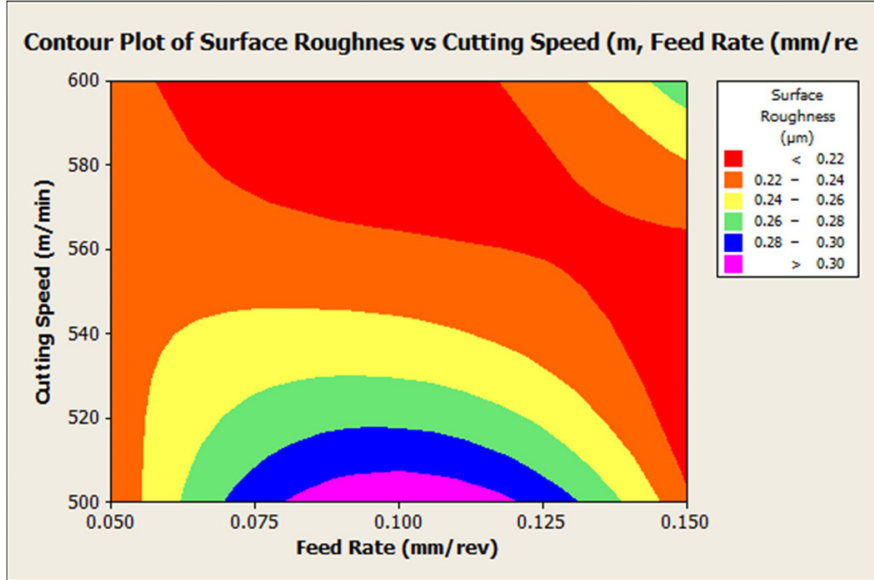

Fig. 4. (b) Response for Surface roughness - Cutting speed vs. Depth of cut

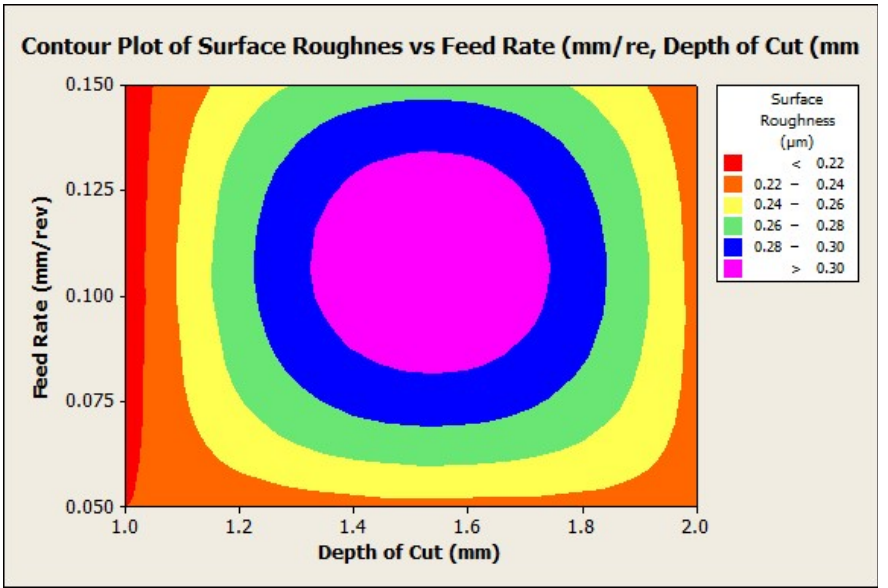

Fig. 4. (c) Response for Surface roughness - Feed rate vs. Depth of cut

The individual responses for surface roughness were shown in Fig. 4a,b,c. This diagram predicts, how different parameters 
affect the surface roughness. Depends upon the speed, feed and depth of cut the value of surface roughness was varied. From above Fig. 4a,b,c region shown red in color possess minimum surface roughness and indicates that the surface was smooth as compared to other regions. Fig. $4 \mathrm{~b}$ reveals that higher cutting speed and lower feed produces better surface finish. Increased feed increases the surface roughness value. This is due to rapid tool movement which deteriorates the quality of the tool and machined surface. The analysis of contour plot shows improved surface roughness which was obtained at higher speed and lower feed rate [15].

\subsubsection{Response for flank wear}

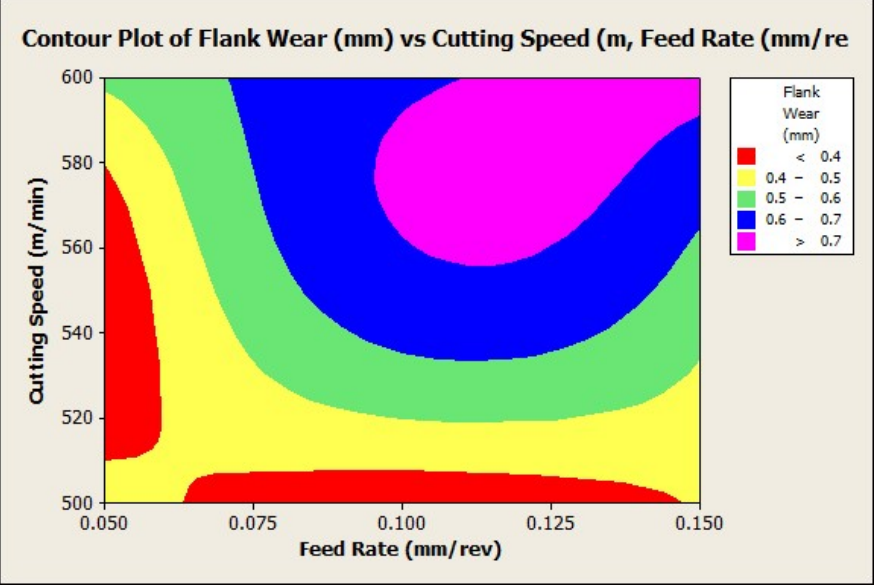

Fig. 5. (a) Response for Flank wear - Cutting speed vs. Feed rate

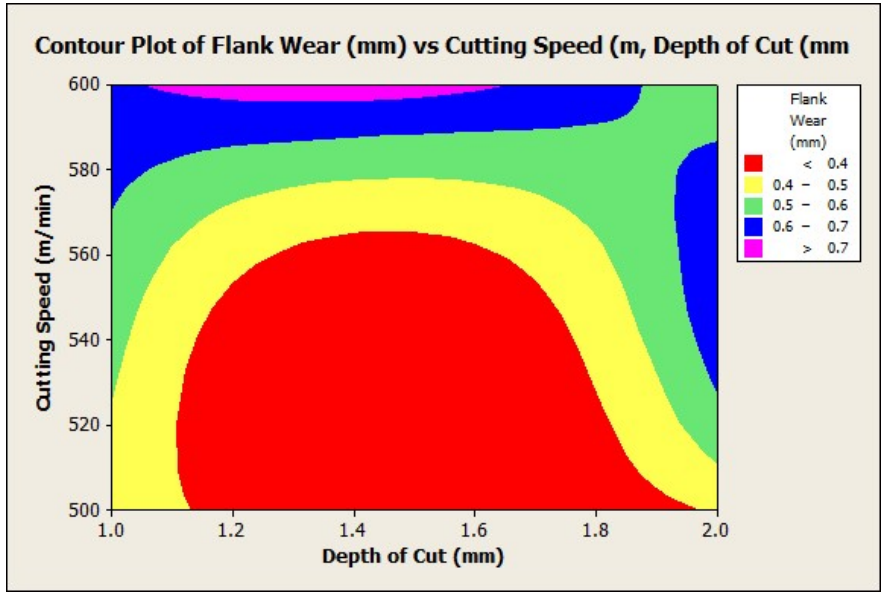

Fig. 5. (b) Response for Flank wear - Cutting speed vs. Depth of cut

The individual responses for flank wear were shown in Fig. 5a,b,c. Depends upon cutting speed, feed rate and depth of cut, flank wear was varied while machining. From the above Fig. 5a,b,c the red color region possess lower flank wear than other regions. From the figures of counter plots cutting speed was the most influencing parameter followed by feed rate and depth of cut. Higher tool flank wear was noticed at increased cutting

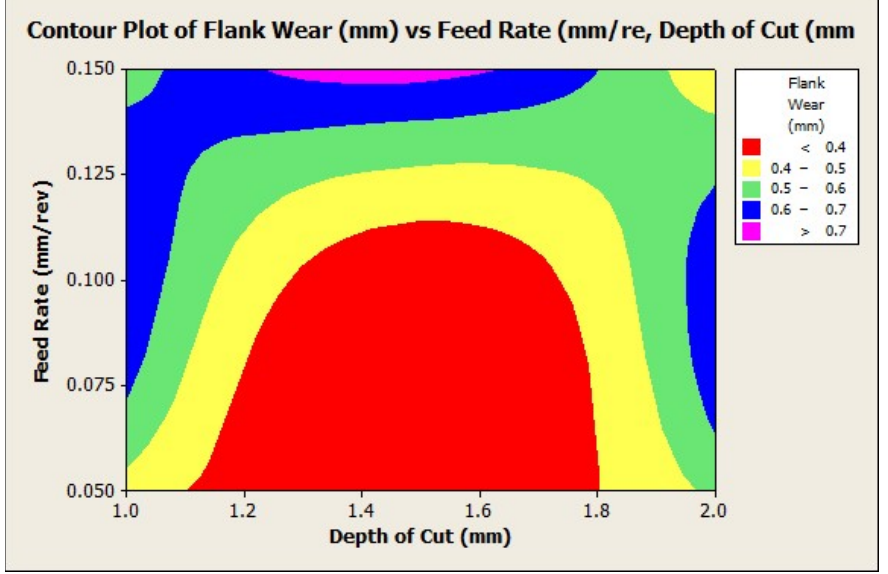

Fig. 5. (c) Response for Flank wear - Feed rate vs. Depth of cut

speed. This is due to increased temperature causing flank wear at tool nose [15]. Tool wear plot shows reduced tool wear at lower values of cutting speed, feed rate, and depth of cut.

\subsection{Discussion of chip formation}

Chip formation was obtained at different cutting conditions as shown in the Fig. 6a,b. Basically, the chip forms in any of the two forms (i) Washer type helical chip and (ii) Arc chip formation which was obtained at various cutting speed and feed rates. In this research work various combination of cutting speed and

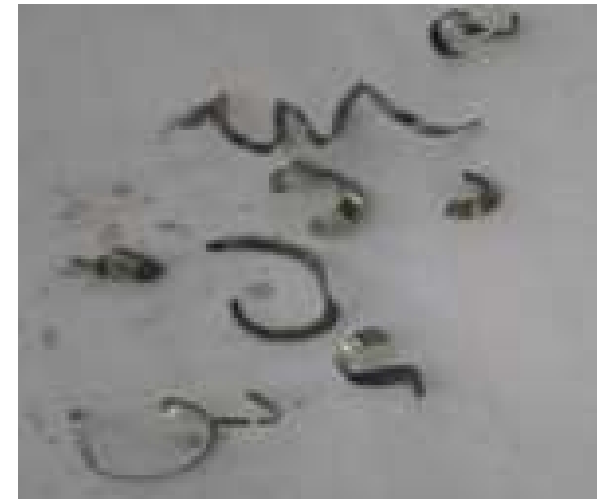

Fig. 6a. Arc chip formation

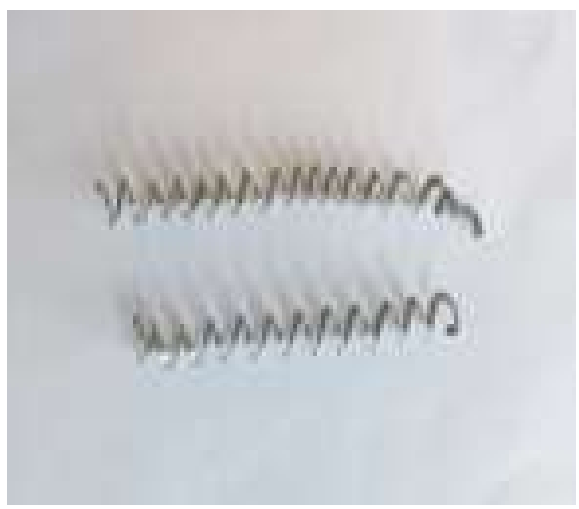

Fig. 6b. Washer type helical chip formation 
1832

feed had been investigated. It was found that the thickness of the chip tends to decrease with decrease in cutting speed for each of the feed. However, the value of an average thickness of the chip also decreases as the feed decreases. Consequently, the feed rate influences the thickness of the chip as the cutting speed acts [9].

The photograph of Arc chip formed during machining under specified cutting parameters (speed $500 \mathrm{~m} / \mathrm{min}$, feed rate $0.05 \mathrm{~mm} / \mathrm{rev}$, depth of cut $2 \mathrm{~mm}$, cutting fluid flow rate-Low) is shown in Fig. 6a. The photograph of washer type helical chip formed during machining under specified cutting parameters (speed $600 \mathrm{~m} / \mathrm{min}$, feed rate $0.1 \mathrm{~mm} / \mathrm{rev}$, depth of cut $1 \mathrm{~mm}$, cutting fluid flow rate-Medium) is shown in Fig. $6 \mathrm{~b}$.

\section{Conclusions}

In this research work, influence of cutting fluid flow rates and cutting parameters on surface roughness and flank wear of TiAlN coated tungsten carbide inserts were investigated by using Taguchi L9 orthogonal array, $\mathrm{S} / \mathrm{N}$ ratio, and analysis of variance (ANOVA). The Depth of cut is the most contributed $(67.55 \%)$ on surface roughness while the cutting speed (45.6\%) is the most contributed to flank wear. The High cutting fluid flow rate was the most effective for reducing surface roughness, while medium flow rate is most effective for reducing flank wear. From the confirmation experiment, the optimum parameters of surface roughness were obtained in medium cutting speed, low feed rate, low depth of cut and high cutting flow rate. For flank wear the optimum parameters was obtained in low cutting speed, low feed rate, medium depth of cut and high cutting flow rate.

\section{REFERENCES}

[1] P. Jindal, A.T. Santhanam, U. Schleinkofer, A.F. Shuster, INT. J. Refract. Met. H. 17, 163 (1999).

[2] J.P. Davim, Springer Science \& Business Media (2011).

[3] H. Tonshoff, C. Arendt, R.B. Amor, Cirp. Ann-Manuf. Techn. 49, 547 (2000).

[4] S.S. Gill, J. Singh, H. Singh, R. Singh, Int. J. Mach. Tool Manu. 51, 25 (2011).

[5] E. Ezugwu, K. Soh, Tribol. Lubr. Technol. 53, 18 (1997).

[6] C.J. Rao, D. Sreeamulu, A.T. Mathew, Arch. Civ. Mech. Eng. 97, 241 (2014).

[7] A.K. Sahoo, S. Pradhan, A.K. Rout, Arch. Civ. Mech. Eng. 13, 27 (2013).

[8] A. Hascalık, U. Caydas, Int. J. Adv. Manuf. Tech. 38, 896 (2007).

[9] S. Debnath, M.M. Reddy, Q.S. Yi, Measurement 78, 111 (2016).

[10] R. Unal, E.B. Dean, International Society of Parametric Analysts (1991).

[11] N. Mandal, B. Doloi, B. Mondal, R. Das, Measurement 44, 2149 (2011).

[12] Y. Sahin, A. Riza Motorcu, Mater. Design. 26, 321 (2005).

[13] A. Kumar, P. Kumar, A. Kumar, B. Singh, Int. J. Res. Eng. Tech. 02, 256 (2013).

[14] V. Gaitonde, S. Karnik, J.P. Davim, J. Mater. Process Tech. 204, 459 (2008).

[15] S.K. Tamang, M. Chandrasekaran, Apem. 10, 59 (2015). 